\title{
THE W. P. FRASER HERBARIUM OF THE UNIVERSITY OF SASKATCHEWAN: PAST, PRESENTAND FUTURE
}

J. HUGO COTA-SÁNCHEZ, E-mail: <hugo.cota@usask.ca>; and VERNON L. HARMS, Department of Plant Sciences, University of Saskatchewan, Saskatoon, SK S7N 5E3, and Department of Biology, University of Saskatchewan, SK, S7N 5E2

\section{Introduction}

The W. P. Fraser Herbarium, whose official acronym is SASK, as registered in the Index Herbariorum, ${ }^{3}$ is an institution devoted to the study of the Saskatchewan flora. In addition to preserving well-documented voucher specimens representing the province's past and present legacy, SASK's primary mission is to provide an accurate taxonomical, geographical, and historical representation of all native and naturalized plants occurring in Saskatchewan. For almost 100 years, SASK has accumulated information regarding the province's natural plant resources. In 2004, SASK was ranked among the top 15 herbaria in the country. ${ }^{1}$ As of 24 March 2009, the collection included 178,624 specimens featuring vascular plants, bryophytes, and lichens. The wealth of information stored in our biological collection is available to systematists and can be used to analyze quantitative data in multiple traditional ways or via biodiversity informatics programs.

The significance of the SASK collection to Saskatchewan biodiversity is evident. The flora of Saskatchewan is essential for scientific research in the areas of plant taxonomy, systematics, and management of botanical collections. However, the lack of qualified personnel in taxonomy and nomenclature is a common problem throughout the world. Indeed, while numerous persons have training and expertise in plant identification, few of them possess the necessary understanding regarding the taxonomic, nomenclatural, and typification rules required in monographic revisions. The shortage of qualified personnel in these areas reflects, in part, the lack of a formal flora book for Saskatchewan, with the exception of the 2003 checklist by V.L. Harms $^{2}$ and the Flora of Saskatchewan Association (FOSA) efforts to produce a provincial flora involving the latest estimation by Harms of ca. 1,600 Saskatchewan species (ca. 1300 native plus approximately 300 exotic species).

Within the educational scope and training of highly qualified personnel, SASK and the University of Saskatchewan are the main learning centres for plant taxonomy, plant systematics, biodiversity, and management of botanical collections. Year round, the herbarium supports undergraduate and graduate-level courses in botany in the departments of Biology and Plant Sciences and reaches out to other educational institutions and the local community. SASK promotes career and work education programs with various local high schools by hosting and educating students for short periods. The herbarium also assists the local community as a part of the museums network and provides workshops, public tours, lectures, and exhibits. As a facility dedicated to the preservation 
and long-term access to research data, the herbarium is an essential information resource centre for students, professionals, amateurs, and the general community.

\section{History and collection development}

SASK is a young institution compared to other Canadian herbaria. The facility is part of the Plant Sciences Department (University of Saskatchewan) and was named after William P. Fraser, who established the herbarium in 1925, building it with collections made by Thomas $\mathrm{N}$. Willing from about 1910 to 1913. Many of Fraser's own collections were added to the Willing nucleus along with those of R.C. Russell (Fraser's colleague in the Canada Agriculture Station, then called the Dominion Laboratory of Plant Pathology).

Between 1919 and 1925, Fraser and Russell had started a herbarium in the Laboratory of Plant Pathology (later to become the Agriculture Canada Saskatoon Experiment
Station), which was merged with SASK in 1981. The merger of Agriculture and Agri-Food Canada, Swift Current (SCS), with SASK in the early 1990s brought in more early Canada Agriculture collections. During the 1930s, Fraser served as a mentor through correspondence with August Breitung, a young amateur from MaKague, SK. These specimens, or duplicates of these, are the Breitung collections with the poor hand-written labels we see in the herbarium vouchers. About a decade later, when Breitung accepted a job at the Agriculture Canada Herbarium (DAO) in Ottawa, he took his own collections with him. In exchange, SASK received about 1000 specimens from DAO, representing the Breitung collections now seen in the SASK collection.

Robert T. Coupland and his graduate students contributed specimens from the late 1940 s through the 1950s and 1960s. Also, numerous collections were made by Andy Skoglund, who was Coupland's

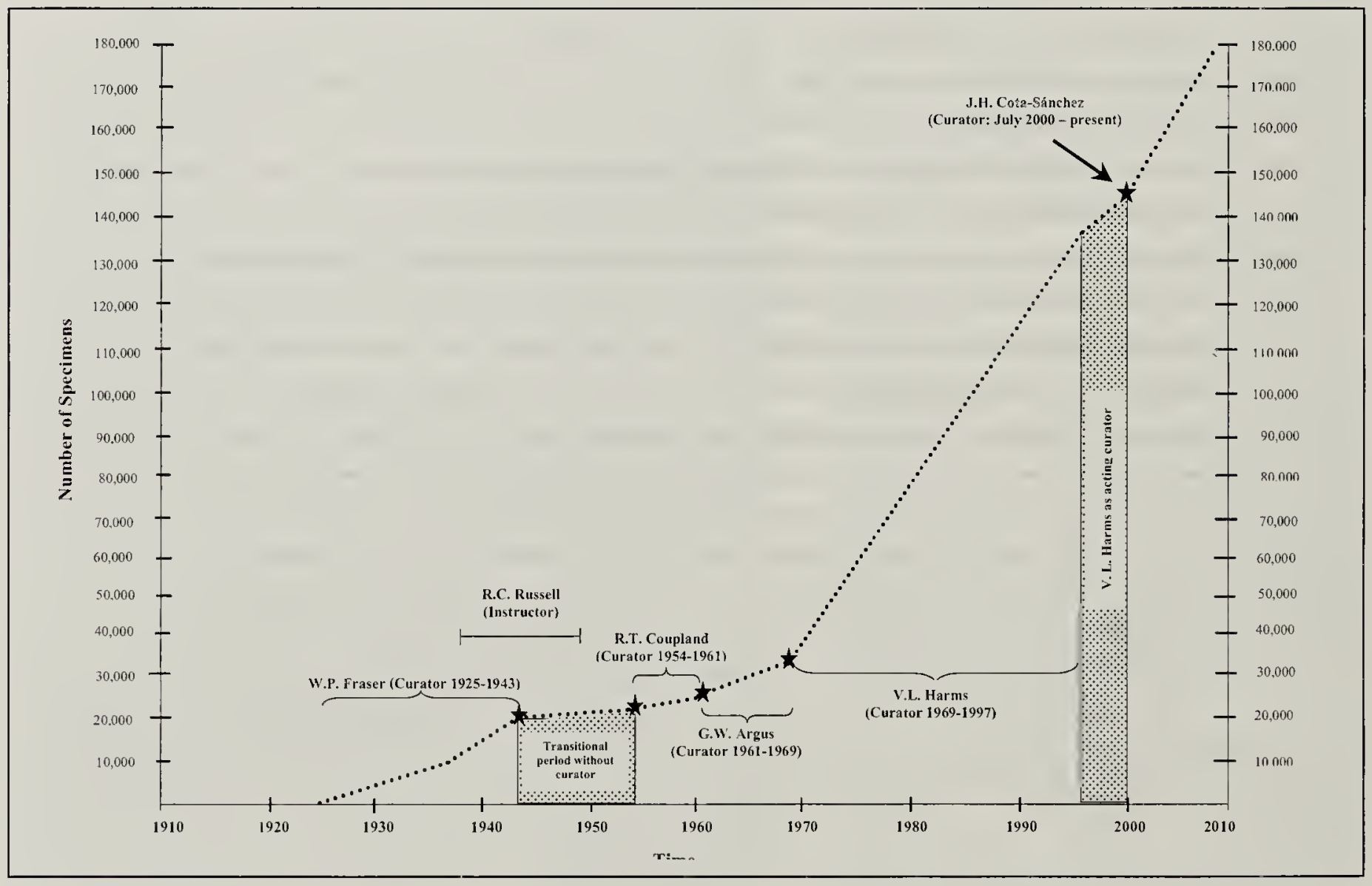

Figure 1. Graphic history of the collection growth and development and chronology of curators in the W. P. Fraser Herbarium (SASK). 
primary technician during his grassland studies in the 1950s and 1960 s and who remained as a departmental assistant, including the role of herbarium technician, until his retirement in 1978. Ralph Dix and his students added vouchers from 1960 to 1966. Later, J. Stan Rowe, who replaced Dix, and his graduate students added collections from the late 1960 s to early 1980 s. In the last 50-60 years, SASK collection development has been possible due to leadership of different curators as well as several devoted Saskatchewan-based botanists, who are included in the next section. The progression in SASK's collection growth to date is shown in Fig. 1.

\section{Main and historical collections hosted at SASK}

With collections covering 125 years, SASK has comprehensive chronological, historical, taxonomic, and geographic coverage of provincial plants, except those from remote, inaccessible areas still in need of botanical explorations (Fig. 2). The type collection and the rare plant database (RPD) are among SASK's representative collections. The type collection includes 47 specimens ${ }^{1}$. The RPD contains 9,656 records with voucher information of taxonomically evaluated rare species housed in the SASK collection and other herbaria. The list includes provincially rare (presumed extinct, endangered, threatened, and most "species of concern" and provincial "candidate" species). In addition to the Saskatchewan Data Centre, no other research institution has such comprehensive information on geographic and taxonomic categorization and rarity status of Saskatchewan plants.

SASK also hosts the main collections of the most significant

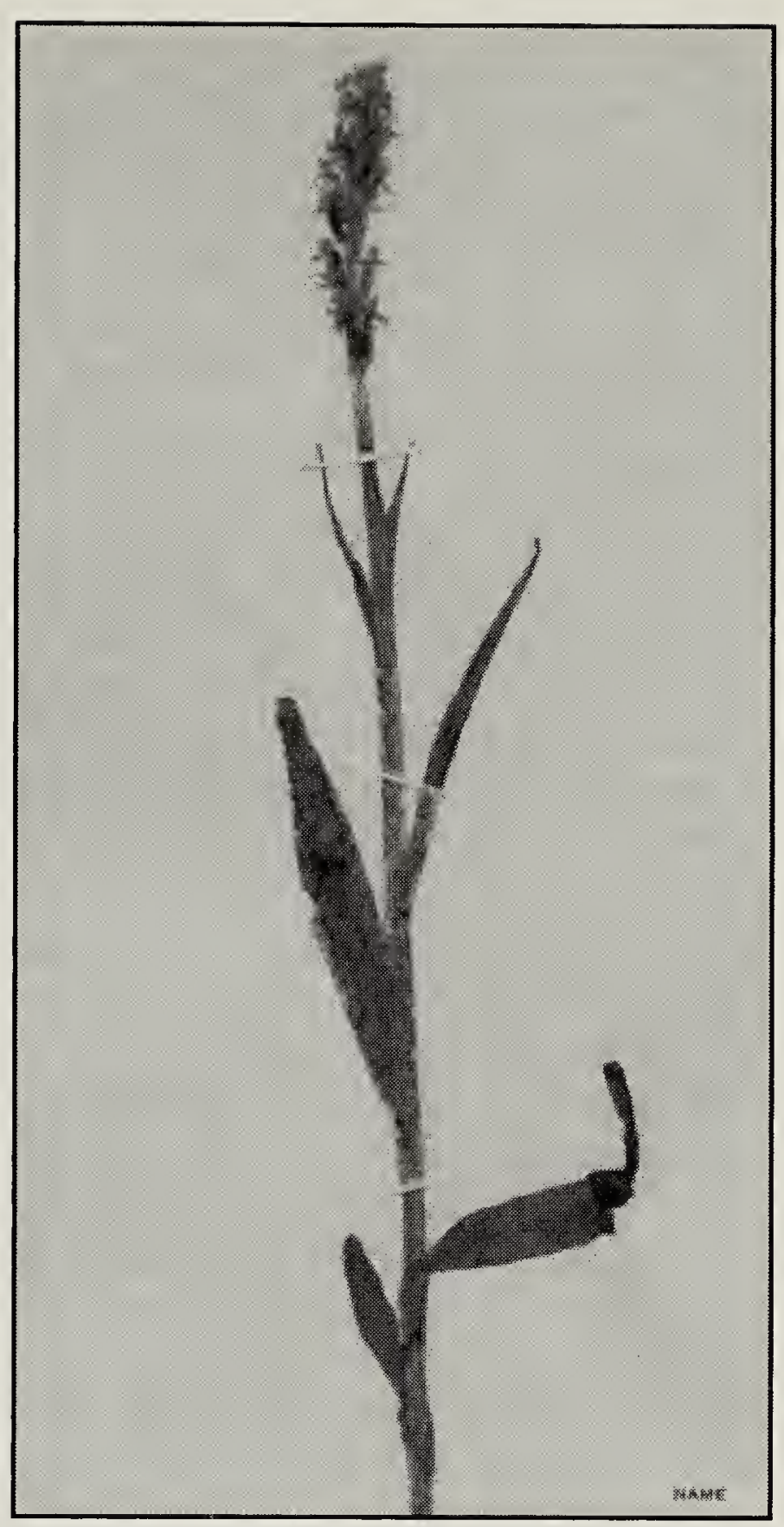

Figure 2. An example of the historical specimens housed in the W. P. Fraser Herbarium (SASK). Northern Green Orchid Platanthera hyperborea collected by Fraser from Prince Albert National Park, SK, in 1933.

Saskatchewan-based collectors, spanning the time period of ca. 1900 to the present. Two collections in particular, those of John Macoun and Thomas N. Willing, have historical value at SASK because they stand as the earliest records of the provincial flora. The Macoun collections came to SASK via exchanges with the Canadian Museum of Nature (CAN) and date from the latter 1890s and early 1900s. Those of Willing were collected in Saskatchewan between 1910 and 1913 or maybe longer. In the same way, 
Table 1. Largest collections hosted at SASK. Estimates were based on SASK Accession Book, which dates back to 2 May 1968. Note that exchange materials and accessions of herbaria merging with SASK were usually recorded in bulk form rather than identifying special collections or main collectors, making some numerical assessments difficult.

\section{Collector Name}

Vernon L. Harms

John H. Hudson

Bernard Boivin George W. Argus

Jan Looman

R. C. Russell

Robert T. Coupland August J. Breitung William P. Fraser

Judy Ternier
6,500

1,700

Unknown

\section{Estimated \# of Accessories}

35,000

Unknown

Unknown

1,000-2,000

Unknown

Unknown

1,000

\section{Collection Information}

From numerous expeditions throughout Saskatchewan from ca. 1993 to 2008.

Cyperaceae, in particular Carex of Saskatchewan. From the 1960s to 2005.

Various plant families.

Contributed the majority of the Salix collections, as well as numerous vouchers of plants collected on various expeditions in northern Saskatchewan in the 1960s. Collected many of the 24,405 accessions from the Agriculture and Agri-Food Canada Herbarium and Semi-Arid Prairie Agriculture Research Centre at Swift Current, SK (SCS), which were merged with SASK in 1991. In the mid-1980s, ca. 7900 specimens of the Can Ag Russell Herbarium were merged with SASK, and many of these were Russell's. Various plant families.

SASK received numerous of his duplicates from DAO.

Fraser collected perhaps one-third to one-half of the ca. 2000 specimens of the original Fraser collection.

Note: the J. and J. Heilman Churchill R. collections are also J. Ternier's, made with Jim Heilman.

A list of the major contributors to SASK collection growth in terms of number of specimens per collector is provided in Table 1.

\section{SASK curators}

The curatorship of the herbarium is a joint position between the Departments of Biology and Plant Sciences. Hence, in addition to the administration and curation of the 


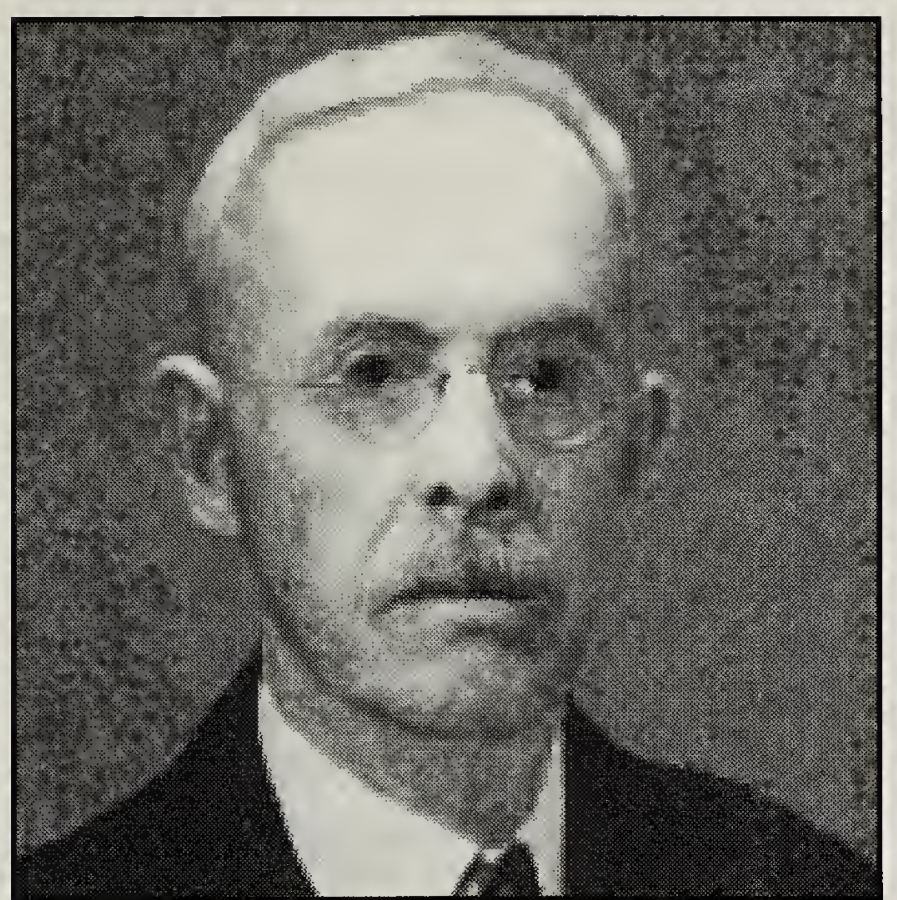

Figure 3. Portrait of William P. Fraser. Date unknown.

facility, curators are responsible for teaching undergraduate and graduate courses in the areas of botany and plant systematics. A chronology of the herbarium embraces the following curators.

William P. Fraser (Fig. 3) became the first curator of SASK in 1925 when he was appointed as a professor of biology. He maintained his collections in the biology department until his death in 1943.

In 1954, Robert T. Coupland was appointed in the College of Agriculture as a plant ecologist and weed specialist. He rescued Fraser's collections and transferred to the Department of Plant Ecology (College of Agriculture). Coupland devoted his time to the curation of his own collections and the Fraser collection until he left the curatorship in 1961.

George W. Argus became curator in 1961 and held this position until 1969. During his curatorship, the Fraser specimens and Coupland's plant ecology collections were fully merged, and our facility became officially recognized as the "W. P. Fraser Herbarium."
In 1969, Vernon L. Harms (see Fig. 4) became the curator until his retirement in 1997. He then carried on as acting curator until June 2000. During his curatorship, SASK experienced a substantial collection growth, due in part to the merging of the Russell Herbarium (Agriculture Canada in 1986) and Swift Current Herbarium (in 1991) with SASK. These two herbaria contributed 32,200 collections with 7,800 and 24,400 specimens, respectively, in addition to other smaller collections, which also merged with SASK.

In July 2000, J. Hugo Cota-Sánchez (see Fig. 4) was appointed as a professor in biology and curator of the herbarium. Since then, SASK has seen a collection increase of 29,588 specimens and has implemented computerized technology, which is described in the following section. A historical progression of the herbarium curatorship and collection development is shown in Fig. 1.

\section{Present and future directions}

Traditionally, SASK has been and will continue to be an institution devoted to preserving and contributing to the

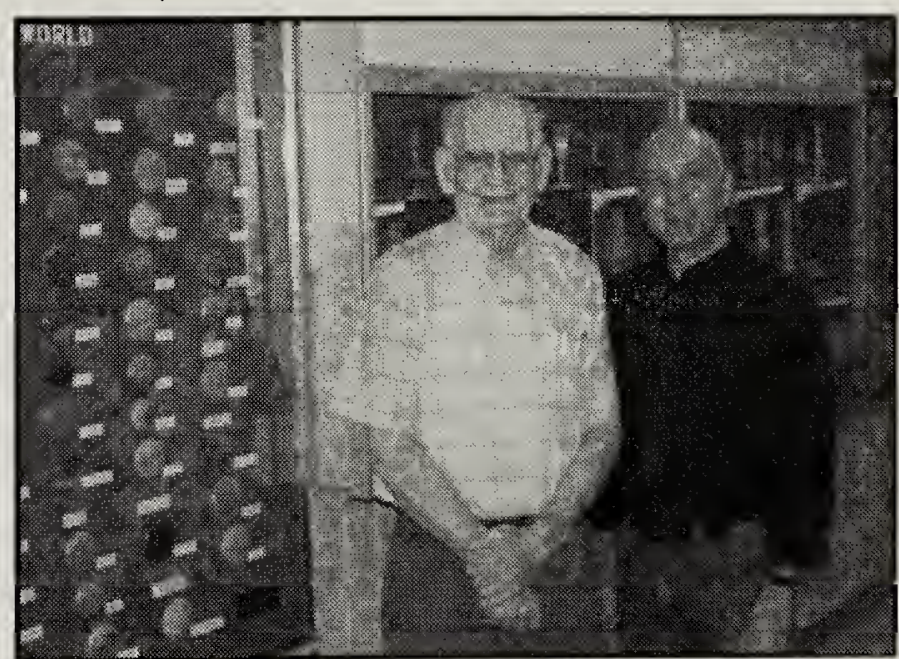

Figure 4. Vernon L. Harms (former curator, left) and J. Hugo CotaSánchez (current curator, right). In the background can be seen part of August Breitung's World Wood Collection. 
knowledge and cataloguing of the local and Canadian flora (Fig. 5). Our museological activities involve collection development, loans and exchange programs, and research and public support, among others. However, in the last 8 years, SASK has undergone several important changes while maintaining its traditional endeavors. In this respect, the current curator is leading the facility's new research directions in biodiversity informatics, a research program built with grants funded by provincial and national agencies, such as FOSA, Museum Assistance Program, Canadian Heritage Information Network, and the Canadian Foundation for Innovation.

SASK's biodiversity informatics research program entails the management of the collection using Specify software to make the specimen label information available online. Specify is an interoperable platform for sorting/managing biodiversity and natural history collections and is used in other herbaria/museums around the world. SASK is one of the leading Canadian institutions implementing Specify in its biodiversity-based research program, which will strengthen provincial and national taxonomic expertise to ensure the long-term conservation of Canadian biodiversity.

SASK's ongoing efforts include the development of an electronic database based on information of the ca. 180,000 collection specimens, which are the foundation for nomenclature and are permanent records of our natural heritage serving as a testimony of the existence of the Saskatchewan plant species in the wild. This database will contribute valuable datasets relevant to taxonomy, biodiversity, conservation, and environmental biology. Specifically, it will provide concise systematic information documenting the province's past and present plant diversity, which, in conjunction with present and future botanical

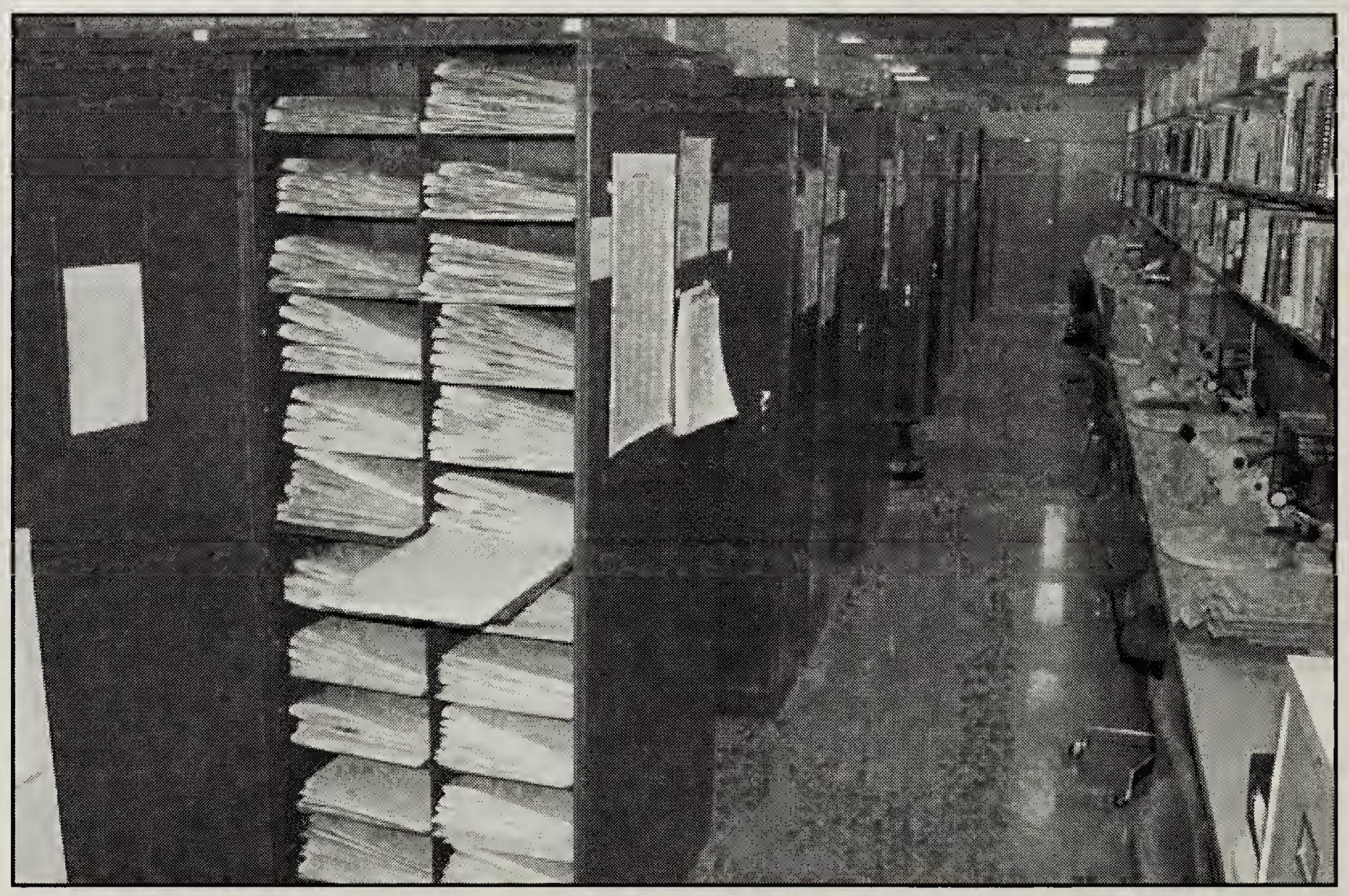

Figure 5. General view of the W. P. Fraser Herbarium (SASK) collection, which contains nearly 180,000 specimens. 
explorations, will enhance the current knowledge of the province's plant resources. In addition to enriching the management and delivery of the SASK botanical collection, the database will expand our knowledge regarding plant history, species diversity, and distribution by allowing us to target hotspot areas to prioritize the holistic study of species and propose habitats/areas for conservation. Overall, the database infrastructure will enable a synergistic cross-analysis of biodiversity data from each group of plants and will greatly enhance our capacity to evaluate ecological and environmental links.

Other major improvements in the herbarium include the use of new preservation and preparation techniques of voucher specimens for collection growth and development as well as new computers and ancillary supporting digital equipment. For instance, the current preparation and preservation of specimens for the collection is being made using environmentally friendly chemicals, such and non-toxic glue and the elimination of moth-balls made of naphthalene, which has a characteristic unpleasant smell and causes respiratory problems. The herbarium research support now includes computer stations in addition to SASK's own server and computers, which have been established to facilitate the updating and the backing up of the database while assisting research and collection access to the scientific and general community. Also, a flatbed scanner for digitization of voucher specimens has been installed in the research area. The computer workstations are strategically located in the herbarium collection room and are fundamental for the data entry and online delivery of the collection. We invite our readers to visit our website (http://herbarium.usask.ca/) and learn more about the herbarium. Our website provides a wealth of information about Saskatchewan plant resources and other data. A new digital gallery and a list with botanical descriptions of the provincial rare species will be launched later this year.

In summary, present and future goals of the biodiversity informatics program at SASK include but are not limited to the following: 1) develop the collection and infrastructure, 2) facilitate the mobility of existing data stored in our biological collection, 3) digitize the herbarium collection and develop a geomapping system for the geographic location of voucher specimens, 4) increase research efficiency for internal and external users by providing fundamental plant and vegetational data that can be used to address a number of problems, such as rarity status and range of invasive and native species, and effect of environmental and landscape changes on species distribution, and 5) provide basic information and tools for diverse biodiversity modeling programs dealing with the flora and vegetation of Saskatchewan. To achieve the above objectives, SASK became part of a partnership known as the Canadian University Biodiversity Consortium (CUBC/Canadensys). The ultimate goal of this network is the online documentation of Canadian biodiversity and represents a synergistic interinstitutional effort to overcome the problems faced by the global decline of taxonomic expertise and the need for rapid identification and organization of biodiversity data. The interoperability of the biodiversity databases in Canadian institutions will facilitate and render our biological collections and their information more accessible to researchers throughout the world.

In conclusion, the herbarium biodiversity informatics research 
program will produce useful electronic catalogues of the provincial flora, because the SASK collection remains a fundamental, rich source of historical, ecological, geographical, morphological, and taxonomic data. SASK databases will greatly facilitate the extraction of such data for use in a wide diversity of taxonomic and conservation-oriented research at the provincial and national levels.
1. COTA-SÁNCHEZ, J.H., R. OLSON, and J. HARALDSON. 2004. The type collection of the W. P. Fraser Herbarium. Polibotánica 17:131-138.

2. HARMS, V.L. 2003. Checklist of the Vascular Plants of Saskatchewan and the Provincially and Nationally Rare Native Plants of Saskatchewan. University Extension Press, University of Saskatchewan, Saskatoon, SK.

3. HOLMGREN, P. K., and N. H. HOLMGREN. 1998. Index Herbariorum: A global directory of public herbaria and associated staff. New York Botanical Garden's Virtual Herbarium. http:/l sweetgum.nybg.org/ih/

\title{
THE GEORGE F. LEDINGHAM HERBARIUM, UNIVERSITY OF REGINA
}

\author{
ELIZABETH BARKER, LB 152, University of Regina, 3737 Wascana Parkway, \\ Regina, SK, S4S 0A2; E-mail: <barker1e@uregina.ca>
}

The George $F$. Ledingham Herbarium was founded in 1945 by Dr. George Ledingham and was named after him in 1990. George remained an active curator of the Herbarium until well into his 90 s and, when he became unable to tend the Herbarium daily, continued to visit occasionally.

The Herbarium houses approximately 50,000 vascular plant specimens, 10,000 bryophytes, and 10,000 mosses, collected from 1901 to the present. A special Grasslands National Park collection, comprising a few hundred specimens, was set up by George, to whom the Park project was near and dear. A new (2008) addition to the Herbarium is a number of plants collected at White Butte by Inga Hiiesalu, a Master's student supervised by Dr. Scott Wilson of the University of Regina.

One Herbarium cabinet is filled with Astragalus, a genus on which George did a great deal of research. This genus, which belongs to the family Fabaceae, includes numerous species of milkvetch, locoweed, and goat's-thorn. A particularly interesting specimen is Astragalus ledinghamii, collected by George in Iran in 1965 and named after him by R. C. Barneby (Fig. 1). George noted that in the area where he collected $A$. ledinghamii, the land was potentially fertile but barren from overgrazing. "Now the goats (millions), sheep, donkeys [and] camels travel about eating every blade of grass as soon as it comes out of the ground. The grass never matures seed and soon disappears," he wrote. One Iranian told George that he had come 20 years too late because the large, thorny species of Astragalus in the locale were being used for firewood.

During the winter of 2006, George attended a coffee social held by the Department of Biology. A few years earlier, as an undergraduate student taking a course in plant taxonomy, I had studied specimens in the Herbarium, profiting from George's expertise and enjoying his friendliness and his enthusiasm for plants. I was happy to see him again and sat down to chat with him. I don't think George knew who I was, but he was determined to 